\title{
As professoras da sala comum e seus dizeres: atendimento educacional especializado nas salas de recursos multifuncionais
}

\author{
Andréia Heiderscheidt Fuck* \\ Aliciene Fusca Machado Cordeiro**
}

\section{Resumo}

Este trabalho apresenta os dizeres das professoras da Sala Comum sobre o Atendimento Educacional Especializado (AEE) nas Salas de Recursos Multifuncionais (SRM). Tem como objetivo principal investigar o que as professoras sabem e esperam deste atendimento no contexto escolar. Para a construção dos dados, utilizouse a aplicação de questionários a 144 docentes do $1^{\circ}$ ao $5^{\circ}$ ano da rede municipal de Joinville, os dados foram analisados por meio da análise de conteúdo de Franco (2012). Os resultados indicam que as professoras da Sala Comum sabem que o AEE nas SRM destina-se aos alunos público-alvo da Educação Especial e tem como um dos objetivos disponibilizar recursos e adaptaçóes, porém, esperam que este possa eliminar as necessidades/dificuldades dos estudantes para desenvolver a aprendizagem. Concluiu-se que as questóes apontadas pelas professoras pesquisadas mostram-se coerentes com as funçôes do professor especializado, desde que se entenda que esta é uma responsabilidade que perpassa toda a organização escolar, envolvendo os profissionais inseridos neste processo. Evidenciou-se, ainda, a insuficiência de troca/parceria entre as professoras da SRM e da Sala Comum, assim como a necessidade de maiores informações e formações no contexto escolar que tenham como foco o trabalho docente numa perspectiva colaborativa.

Palavras-chave: Trabalho docente; Salas de recursos multifuncionais; Atendimento educacional especializado.

* Professora da Rede Municipal de Joinville. Joinville, Santa Catarina, Brasil.

** Professora doutora da Universidade da Regiáo de Joinville. Joinville, Santa Catarina, Brasil. 


\section{Ordinary classroom teachers and their sayings: specialized educational services in multifunctional resources classrooms}

\section{Abstract}

This paper presents what Ordinary Classroom teachers say about Specialized Educational Services (SES) in Multifunctional Resources Classrooms (MRC). Its main goal is to investigate what these teachers know and expect regarding this service in the school context. For data construction, questionnaires were applied to 144 teachers from 1 st to 5 th year of public municipal schools of Joinville and were analyzed based on a content analysis method proposed by Franco (2012). Results show that Ordinary Classroom teachers know that SES in MRC are intended to students considered as target-audience of Special Education and has, as one of its objectives, to provide resources and adaptations. However, they expect that this service eliminates these student's needs/difficulties in order to develop learning. It was concluded that issues raised by the teachers who participated of this research seem consistent towards the actual functions of specialized teachers, but it's imperative to understand that this responsability permeates the entire school organization, involving all professionals inserted in this process. Still, the insufficiency of exchange/partnership between Ordinary Classroom teachers and MRC teachers was evident, as well as the need for more information and formation in the school context, that focuses on teacher's work in a collaborative perspective.

Keywords: Teacher's work; Multifunctional resources classrooms; Specialized educational services.

\section{Introdução}

Conforme os estudos de Baptista (2011), a Sala de Recursos Multifuncionais destaca-se, na atualidade, como prioridade na oferta de serviços especializados no espaço escolar. Neste contexto, instaura-se um amplo debate sobre suas diretrizes na escola, sua organização pedagógica, seus profissionais, suas açôes complementares e suplementares.

Estas discussóes se intensificaram com a Política Nacional de Educação Especial na perspectiva da Educação Inclusiva - PNEE-EI de 2008, com indicativos de que o Atendimento Educacional Especializado (AEE) não deveria substituir, mas complementar ou suplementar o ensino em classes comuns, assim como a Resolução n. 04/2009 do CNE que define as diretrizes do AEE, e em seu art. $1^{\circ}$ regulamenta que:

$\$ 1^{\circ}$ Os sistemas de ensino devem matricular os estudantes com deficiência, transtornos globais de desenvolvimento e altas habilidades/superdotação nas classes comuns do ensino regular e no atendimento educacional especializado (AEE), complementar ou suplementar à escolarização ofertado em sala de recurso multifun- 
cional ou em centros de AEE da rede pública ou de instituições comunitárias, confessionais ou filantrópicas sem fins lucrativos. (BRASIL, 2009, p. 1).

Entretanto, o processo de implantação das Salas de Recursos Multifuncionais teve início bem antes, com o Programa Educação Inclusiva - Direito à Diversidade (2003-2010), que possibilitou a formação de gestores e educadores nos municípios brasileiros, intensificando a relação entre a Secretaria da Educação Especial e uma rede de municípios pólo nos diferentes estados. O município de Joinville, lócus de investigação do presente trabalho, iniciou como município polo em 2007 e recebeu as primeiras nove Salas de Recursos Multifuncionais no ano de 2009, contando com 42 Salas já implantadas até 2013, ano de construção dos dados da presente pesquisa.

No tocante a implantação das Salas de Recursos Multifuncionais nas escolas municipais, Joinville segue as diretrizes Nacionais de Educação e a PNEE-EI de 2008. Diante destas regulamentaçóes, a escola se vê frente a uma nova modalidade que deve funcionar preferencialmente dentro da própria escola, mas que exige da mesma repensar suas ações e reorganização de suas estruturas para que este atendimento se realize, a começar pelo próprio projeto político pedagógico (PPP). Questiona-se, contudo, se esta modalidade de ensino contribuirá para a reestruturaçâo das açóes pedagógicas nas salas comuns e, consequentemente, uma mudança nas estruturas organizativas da escola.

Tendo em vista o que é preconizado nos documentos oficiais, torna-se necessário conhecer, discutir e entender a organização do AEE nas SRM no contexto escolar, sobretudo porque este atendimento vem acompanhado de normatizaçóes, políticas, documentos norteadores que devem servir para balizar o trabalho docente em relação ao aluno atendido, mas que na maioria das vezes se embatem com a sistemática já estabelecida neste espaço, com as condiçôes do trabalho docente, com as realidades locais e até mesmo com as formas tradicionais de organização, a qual historicamente as escolas, e consequentemente os seus profissionais, constroem suas práticas pedagógicas e embasam suas concepçóes.

Com a finalidade de contribuir com as discussōes na área da Educação Especial tendo como foco este serviço oferecido aos estudantes com deficiência, este trabalho tem como objetivo investigar o Atendimento Educacional Especializado nas Salas de Recursos Multifuncionais nos dizeres das professoras ${ }^{1}$ da Sala Comum.

\section{Delineamento dos caminhos metodológicos da pesquisa e seus participantes}

Para o desenvolvimento desta pesquisa, adotou-se alguns pressupostos da base epistêmica metodológica do materialismo histórico e dialético que "percebe os sujeitos como históricos, datados, concretos, marcados por uma cultura como criadores de ideias e consciência que, ao produzirem e reproduzirem a realidade social, são ao mesmo tempo produzidos e reproduzidos por ela" (FREITAS, 2002, p.22). 
Com esta percepção de sujeito, pretendeu-se, com esta pesquisa, ampliar-se os conhecimentos em relação à Educação Especial do Município de Joinville, contribuindo para sua efetivação e, ao mesmo tempo, provocar análises e reflexôes. Neste sentido, adotou-se a metodologia de abordagem qualitativa, pois esta corrobora com a concepção de sujeito destacada, concorda-se com André quando diz que:

Cada vez mais se entende o fenômeno educacional como situado dentro de um contexto social, por sua vez inserido em uma realidade histórica, que sofre toda uma série de determinaçóes. Um dos desafios atualmente lançados à pesquisa educacional é exatamente o de tentar captar essa realidade dinâmica e complexa do seu objeto de estudo, em sua realização histórica. (ANDRÉ, 1986, p. 5).

Devido ao elevado número de participantes, constituiu-se numa pesquisa do tipo survey. Atualmente, este é um dos métodos empregados com maior frequência na pesquisa social. Importante esclarecer que o método survey pode ser relacionado à pesquisa quantitativa, qual não é a intenção deste trabalho, portanto, este foi utilizado como um instrumento que nos possibilitou coletar as informaçôes que, por meio de uma análise qualitativa, passaram a representar as opiniôes e concepções dos participantes.

Para realizar esta investigação, delimitou-se como lócus todas as escolas municipais com turmas do $1^{\circ}$ ao $5^{\circ}$ ano. Definiu-se que os participantes da pesquisa seriam professores da Sala Comum que no ano de 2013 haviam tido ou tivessem alunos em atendimento na Sala de Recursos, para análise dos dados obteve-se 144 respondentes. O instrumento utilizado para a construção dos dados foi um questionário autoaplicável, contendo dezoito questóes abertas e fechadas. Esta pesquisa adotou como método de análise dos dados a Análise de Conteúdo (FRANCO, 2012), pois se entende que este procedimento nos permite valorizar o material a ser analisado, abrindo possibilidades de contextualizá-lo. Para a organização dos dados, todas as questôes foram transcritas para planilhas do programa Excel. Os questionários foram identificados por meio de uma letra e um número, que formaram uma nominaçáo para cada sujeito de pesquisa (Participante $1=\mathrm{P} 1$; Participante $2=\mathrm{P} 2$, e assim sucessivamente).

Após a digitação de todos os questionários, as planilhas das questôes abertas foram impressas para se dar início à codificação, classificação e categorização dos dados. Com as questóes impressas, passou-se para a leitura atenta de todo o material. Após a primeira leitura, leu-se novamente, dando início ao processo de identificação dos pré-indicadores de cada questáo. Depois, ocorreu a elaboração dos pré-indicadores de cada pergunta. Com estes, criou-se uma legenda, estabelecendo uma cor para cada pré-indicador, e todas as respostas da questão foram pintadas, conforme a cor correspondente ao pré-indicador. Por último, aproximaram-se os participantes de cada questão pela cor das respostas, para que as respostas semelhantes pudessem ficar agrupadas. Assim, construíram-se quadros com os pré-indicadores e as respostas dos participantes.

A partir da leitura atenta e minuciosa dos quadros, construíram-se as categorias de análise e discussóes das questóes apresentadas pelas participantes da pesquisa. 


\section{Os dizeres das professoras da sala comum sobre o atendimento educacional especializado nas salas de recursos multifuncionais no contexto escolar}

Nos dizeres das professoras da Sala Comum sobre o que sabem sobre o AEE nas SRM, evidenciou-se que as respostas centraram-se em três questôes: no atendimento aos alunos com deficiência, nos recursos e adaptaçóes e para eliminar as necessidades/dificuldades. Todavia, a maioria das participantes da pesquisa, dizem que este se destina ao atendimento dos alunos com deficiência:

Sei que é trabalho realizado de forma complementar, extraclasse, com alunos que possuem alguma deficiência, transtorno no desenvolvimento, acredito que possa ser realizado com alunos com altas habilidades $e$ superdotados (P12).

Para alunos com deficiências onde se trabalha as funçöes psicológicas superiores, contribuindo para o acesso ao conhecimento. Säo atividades de complementação e suplementação (P 50).

As falas das participantes da pesquisa se relacionam com os objetivos explícitos na PNEE-EI de 2008, que descreve como público-alvo deste atendimento os alunos com deficiência, transtornos globais do desenvolvimento e altas habilidades/superdotação nas escolas regulares, orientando os sistemas de ensino para promover respostas às necessidades educacionais especiais, esclarecendo que:

Considera-se pessoa com deficiência aquela que tem impedimentos de longo prazo, de natureza física, mental ou sensorial que, em interação com diversas barreiras, podem ter restringida sua participação plena e efetiva na escola e na sociedade. Os alunos com transtornos globais do desenvolvimento são aqueles que apresentam alteraçōes qualitativas das interaçóes sociais recíprocas e na comunicação, um repertório de interesses e atividades restrito, estereotipado e repetitivo. Incluem-se nesse grupo alunos com autismo, síndromes do espectro do autismo e psicose infantil. Alunos com altas habilidades/superdotação demonstram potencial elevado em qualquer uma das seguintes áreas, isoladas ou combinadas: intelectual, acadêmica, liderança, psicomotricidade e artes, além de apresentar grande criatividade, envolvimento na aprendizagem e realização de tarefas em áreas de seu interesse. (BRASIL, 2008, p. 9).

A segunda questão mais apontada foi o trabalho com foco nos recursos e adaptaçóes, que se mostra em consonância com uma das funçôes do AEE, conforme a Resolução 04/2009 CNE-CEB, quando afirma que:

Art. $2^{\circ} \mathrm{O}$ AEE tem como função complementar ou suplementar a formação do aluno por meio da disponibilização de serviços, recur- 
sos de acessibilidade e estratégias que eliminem as barreiras para sua plena participação na sociedade e desenvolvimento de sua aprendizagem. (BRASIL, 2009, p. 1).

Constata-se que as falas das professoras estão de acordo com os documentos em ambos os aspectos destacados, tanto no que se refere ao público-alvo quanto em concordância com as funçóes do AEE nas SRM no espaço escolar. Sobretudo quando as professoras destacam os recursos e adaptaçóes como uma das formas de eliminar as barreiras do estudante com deficiência no espaço escolar.

Todavia, entende-se que os recursos e adaptaçôes devem ser ajustados às necessidades dos estudantes, oportunizando-os desenvolver suas potencialidades, portanto, não existe um padrão único para seu uso, assim como náo significa que toda pessoa com deficiência necessariamente necessite deles, ou ainda que tudo deva ser adaptado, mas que estes devem ser personalizados, visando à autonomia da pessoa. Para além desta autonomia, entender que os recursos e adaptaçóes constituem-se em meios, pois, o que deve ser fundamentalmente garantido ao aluno com deficiência é o seu direito de acesso aos conteúdos escolares. Desta forma, concorda-se com Garcia (2013), quando afirma que ainda que se considere a complexidade das aprendizagens que derivam do uso de recursos específicos e o trabalho que isso demanda da escola, em termos de mudanças em sua dinâmica cotidiana, é preciso que sejam ressaltados os riscos que podem emergir de uma leitura simplificadora do processo de escolarização dos estudantes com deficiência numa concepção equivocada em que adaptar, ou disponibilizar recursos, seja sinônimo de reduzir os conhecimentos escolares, colocando o aluno em situação de desvantagem na aquisição dos conteúdos.

$\mathrm{Na}$ verdade, para além da aquisição, do conhecimento e utilização dos recursos e adaptaçóes no espaço escolar, encontram-se as concepçóes dos profissionais envolvidos no processo de escolarização dos alunos com deficiência referentes às possibilidades deste aluno aprender e se desenvolver, pois são as suas crenças que o mobilizarão a acreditar no aluno e, assim, buscar alternativas para a sua plena participação nas atividades desenvolvidas e, quando necessário, utilizar os recursos e adaptaçôes que eliminem as barreiras impostas pelo ambiente escolar. $\mathrm{O}$ recurso só tem viabilidade a partir da credibilidade no potencial do aluno.

Evidencia-se, por meio dos dizeres das professoras da sala comum, que há o reconhecimento da importância da utilização de diferentes recursos para aprendizagem do aluno com deficiência. Assim, entende-se que os recursos e adaptaçóes podem constituir-se em valor favorável ao desenvolvimento do trabalho do professor da SRM em articulação com o trabalho docente realizado na sala comum. Entretanto, para que o recurso possa ajudar a eliminar as barreiras, é necessário que não fique restrito ao espaço da SRM, mas faça parte do contexto escolar do aluno, neste caso, torna-se necessário o estabelecimento do trabalho em rede, da troca, da parceria, enfim, um trabalho que se constitua de forma colaborativa. Nóvoa diz que

a complexidade do trabalho escolar reclama um aprofundamento das equipes pedagógicas. A competência colectiva é mais que o somatório das competências individuais. Estamos a falar da neces- 
sidade de um tecido profissional enriquecido, da necessidade de integrar na cultura docente um conjunto de modos colectivos de produção e de regulação do trabalho. [...] a ideia da escola como lugar da formação dos professores, como espaço da análise partilhada das práticas, enquanto rotina sistemática de acompanhamento, de supervisão e de reflexão sobre o trabalho docente. O objetivo é transformar a experiência colectiva em conhecimento profissional e ligar a formação de professores ao desenvolvimento de projetos educativos nas escolas. (NÓVOA, 2011, p. 16).

Neste sentido, ressalta-se que a parceria não foi mencionada de forma específica, como uma das principais questóes norteadoras do trabalho do professor especializado, o que pode sinalizar incompreensóes referentes ao uso dos recursos e adaptaçóes, já que estes adquirem seu real valor quando passam a fazer parte da rotina do aluno, para auxiliar na eliminação das barreiras em todos os espaços do ambiente escolar.

A relação dos recursos e adaptaçóes com a necessidade da realização de um trabalho em parceria fica ainda mais evidente quando se correlaciona as falas das respondentes da pesquisa com as funções pedagógicas, contidas no $13^{\circ}$ artigo da Resolução 04/2009 CNE-CEB, que define as atribuiçōes do professor do AEE:

I - identificar, elaborar, produzir e organizar serviços, recursos pedagógicos, de acessibilidade e estratégias considerando as necessidades específicas dos alunos público-alvo da Educação Especial; (grifos meus)

II - elaborar e executar plano de Atendimento Educacional Especializado, avaliando a funcionalidade e a aplicabilidade dos recursos pedagógicos e de acessibilidade; (grifos meus)

VII - ensinar e usar a tecnologia assistiva de forma a ampliar habilidades funcionais dos alunos, promovendo autonomia e participação; (grifos meus)

Entende-se que para a realização das funçôes destacadas referentes às adaptaçóes e recursos, o professor especializado precisa conhecer o aluno, suas possibilidades e, assim, viabilizar o melhor recurso. Sobretudo, precisa verificar sua funcionabilidade na sala comum, pois é neste espaço que se encontram as barreiras que precisam ser eliminadas.

Todavia, percebe-se uma mudança de foco nos dizeres das professoras pesquisadas, quando pontuam as finalidades e o que esperam do AEE nas SRM. Neste momento, ganha destaque a questão necessidades e dificuldades dos estudantes. Para 55 das professoras pesquisadas, a finalidade do trabalho do professor da SRM, assim como o que elas esperam deste, concentra-se em suprir "as necessidades e superar as dificuldades dos estudantes" desta forma, segundo as professoras, o aluno conseguirá: "uma melhora global das suas competências", "desenvolverá as habilidades mentais superiores", "terá mais autonomia", "raciocínio lógico", "desenvolverá as percepçôes", "socia- 
lização", "terá melhora no comportamento", "lateralidade", "alfabetização", sendo que "todo apoio é de suma importância, pois nem sempre estamos preparados para atender essas crianças (P18)". A pesquisa de Jesus (2008) destaca que falas semelhantes a esta última são reiteradas por um número significativo de docentes que atuam nos mais diferentes níveis e nos diversos espaços. Diante desta constatação, a autora questiona a constituição deste discurso de negação, que afirma o despreparo para ensinar estudantes com deficiência, assim como indaga sobre o que fazer para superá-lo.

Não se trata aqui de negar a complexidade de atuar com grupos de alunos que nos colocam o desafio de ensinar na diversidade, nem de banalizar as especificidades que acompanham algumas condiçóes de deficiência. O desafio que se apresenta é tentar instituir outras práticas de potencializaçáo dos saberes-fazeres, de modo que a presença de alunos, em situação de desvantagem, de qualquer natureza, nâo seja paralisadora de açóes docentes. (JESUS, 2007, p. 75).

Contudo, o que as professoras, em sua maioria, esperam é que este atendimento elimine as dificuldades dos estudantes. Fato que pode estar relacionado aos resquícios históricos do processo de integração que antecedeu o processo de inclusão, pois, segundo Machado:

Na perspectiva da integração, a escolarização do aluno da Educação Especial significava admiti-lo em turmas comuns apenas quando estes estivessem "prontos" para acompanhar os demais colegas nas atividades escolares e tendo a orientação e apoio de professores da Educação Especial. (MACHADO, 2013, p. 2).

Assim, o professor da sala comum pode estar preso às concepçóes de normalização, ou seja, pressupóe que por meio do Atendimento Educacional Especializado o aluno terá suas dificuldades amenizadas, ou até mesmo sanadas, e passará a ter o mesmo "padrão" do aluno dito "normal". Deste modo, a deficiência não será mais o impeditivo para que o aluno participe do processo de escolarização. Para Beyer (2009), a inadequaçáo desta prática escolar da educação integradora consistiu sempre na demasiada sobrecarga do sucesso da proposta sobre os esforços de alguns: "o heróico e sacrificado professor, a criança e suas condiçōes pessoais de adaptação, a capacidade da família em dar o suporte necessário" (BEYER, 2009, p. 75). Algumas falas nos ajudam a perceber tais constataçóes, quando referenciam que o AEE nas SRM deve:

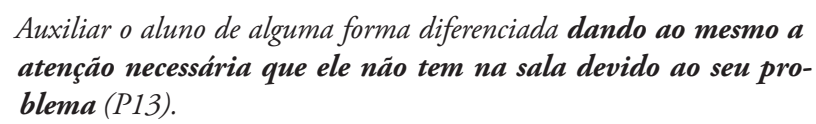

Levar o aluno a superar e avançar em suas dificuldades, desenvolvendo atividades dentro de suas limitaçóes, no entanto, propondo desafios para que participem tranquilamente das aulas junto da turma que está inserido (P23). 
Percebe-se que, ao mesmo tempo em que as professoras explicitam saber que o atendimento tem como função trabalhar com o aluno com deficiência, ajudando no seu processo de escolarização, por meio da disponibilização de recursos, demonstram ter expectativas que, por meio da especialização deste professor e dos diferentes recursos que esta sala oferece, o professor especializado consiga fazer com que o aluno elimine suas necessidades e participe da aula, entenda os conteúdos e melhore seu comportamento. Contudo, observa-se que o professor da sala comum espera do professor especializado soluçóes que não dependem exclusivamente do AEE na SRM, mas que implicam na própria organização estrutural, política e cultural da escola.

Lembrando que o AEE nas SRM tem como objetivo eliminar as barreiras que impedem ao aluno de participar do contexto escolar, entende-se que, para eliminar estas barreiras, não basta apenas trabalhar com o aluno e com as suas necessidades, torna-se necessário, sobretudo, trabalhar com todos os envolvidos no processo de escolarização do aluno com deficiência. Desta forma, é fundamental localizar os processos que engendram o surgimento das dificuldades no processo de escolarização do estudante da Educaçáo Especial, exigindo do espaço escolar uma adequação, um repensar e (re)planejar das atividades por parte dos professores, o suporte da equipe pedagógica e da direçáo, além do apoio de toda a comunidade escolar. Assim, o processo de escolarização do estudante que frequenta a SRM é uma responsabilidade que não é limitada à ação do professor especializado, mas que precisa fazer parte do PPP da escola, a partir do qual todos os profissionais sejam envolvidos no trabalho que resulte no sucesso da educação escolarizada de todos os estudantes.

A segunda questão apontada pelas professoras referente ao que esperam do AEE nas SRM foi: aprendizagem e desenvolvimento do aluno, sendo que esta foi destacada por 32 participantes da pesquisa. $\mathrm{O}$ fato das professoras da sala comum reconhecerem a importância da aprendizagem mostra-se como algo positivo, pois fazer aprender é a principal funçáo da escola. A cilada pode estar em delegar a aprendizagem dos alunos com deficiência exclusivamente ao AEE na SRM, deste modo, concorda-se com Machado,

O ponto de partida para se conceber a educação inclusiva é a condição de igualdade de todos os alunos diante do direito de aprender. O ponto de chegada são as diferenças de aprendizagem dos alunos, que se devem à capacidade e às condições de aprender de cada um e, sem dúvida alguma, à qualidade do ensino que é oferecida a todos. (MACHADO, 2013, p. 64).

Quanto ao ato de aprender, Machado (2013) diz que este pode ser pensado como um acontecimento, não apenas como um produto, como um resultado esperado. Com esta forma de concebê-lo é possível valorizar situaçôes únicas no processo educativo e acreditar que os estudantes sempre podem aprender, pois o aprender não é fixado no tempo, nem totalmente previsto, mas um movimento em direção de níveis mais avançados de entendimento, em que cada momento de aprendizagem tem seu valor para alcançar o próximo. Com este olhar passa-se a vislumbrar além das dificuldades, passa-se a potencializar as possibilidades. Nas palavras de Vygotsky, 
O aprendizado é mais do que a aquisição de capacidades para pensar; é a aquisiçáo de muitas capacidades especializadas para pensar sobre várias coisas. $\mathrm{O}$ aprendizado não altera nossa capacidade global de focalizar a atenção; ao invés disso, no entanto, desenvolve várias capacidades de focalizar a atenção sobre várias coisas. (VYGOTSKY, 2007, p. 108).

As professoras da sala comum explicitam suas expectativas referentes à aprendizagem e desenvolvimento dos alunos e o que elas esperam que seja realizado no AEE na SRM:

Espero que o trabalho desenvolvido favoreça o meu aluno em seu processo de aprendizagem e de vida diária. Bem como me sirva de auxílio para que eu possa atender bem o aluno em sala da forma com que ele precisa, pois as dúvidas e questionamentos sáo muitos (P90).

Ao expor o que esperam referente à aprendizagem dos alunos, as professoras da sala comum vislumbram no professor especializado alguém que trabalhe com o aluno e lhes oriente a como trabalhar com ele em sala de aula. Pois explicitam que precisam de: orientação, auxílio, sugestóes e aconselhamentos. De fato, constitui-se uma das funçóes deste profissional, instituídas nos documentos que o regulamentam, estabelecer articulação com os professores da sala comum. As professoras da sala comum apresentam questóes que, de fato, são balizadoras do trabalho docente do professor especializado, porém, verifica-se contradiçóes, pois o professor da sala comum colocase como um receptor de informaçóes, quando, na verdade, deveria existir uma relação de troca, pois o professor especializado necessita das informaçóes advindas do processo de escolarização que ocorre na sala de aula, para que a partir das barreiras deste espaço e do trabalho individualizado com o aluno, verificando suas potencialidades, possa então propor, sugerir e orientar, numa relação de reciprocidade.

Baptista (2013) defende uma prática do educador especializado que não se restrinja a um determinado espaço físico, muito menos que centralize-se num estudante que precisa ser "corrigido". Ele defende uma ação plural em suas possibilidades e metas, que identifique e modifique as relações que contribuem para a estagnação do sujeito e sua provável dificuldade de aprendizagem e desenvolvimento. Explicita que é possível que se tenha que problematizar o AEE, pois, na sua visão, seria empobrecedor conceber que um conjunto amplo de possibilidades de intervenção ficasse reduzido em um único modelo de SRM.

Entretanto, esta compreensão não deve servir para despotencializar o atendimento, pois como nos diz Baptista (2011), precisamos perceber que algumas das ditas vantagens que eram associadas à classe especial podem ser potencializadas na SRM, como o trabalho com pequenos grupos que deve ser estimulado neste espaço, e que permite o melhor acompanhamento do aluno, favorecendo as trajetórias de aprendizagem mais individualizadas sob a supervisão de um docente que se espera, tenha formação específica. "No caso da sala de recursos, a grande vantagem é que esse processo tem condiçóes de alternância contínua com aquele desenvolvido na sala de aula comum" (BAPTISTA, 2011, p. 70). 
A terceira questão apresentada nos dizeres das professoras referentes ao que esperam do AEE nas SRM foi troca e parceria. Os dados apresentados evidenciam que náo faz parte da organização escolar, do planejamento das professoras, terem um momento específico para que se estabeleça um trabalho de parceria e troca entre os professores. Salienta-se, sobretudo, que o maior prejudicado é o estudante com deficiência, pois, sem a troca e parceria, o trabalho docente realizado na SRM fica desvinculado do trabalho realizado na sala comum. Nas palavras de Mendes,

O ensino colaborativo ou co-ensino, é um modelo de prestação de serviço de educação especial no qual um educador comum e um educador especializado dividem a responsabilidade de planejar, instruir, avaliar a instrução a um grupo heterogêneo de estudantes. [...] O objetivo é o de criar opçôes para aprender e prover apoio a todos os estudantes na sala de aula de ensino regular, combinando habilidades do professor comum e do professor especializado. (MENDES, 2008, p. 107).

Evidencia-se que é a necessidade que faz com que o professor da Sala Comum busque alternativas para trabalhar com o aluno com deficiência na sala, dentre elas ir à Sala de Recursos Multifuncionais, contudo, esta prática parece não fazer parte do seu planejamento. Sem uma organização antecipada, entende-se que as atividades vão acontecendo e as adaptaçốes vão sendo feitas quando possível, o que inviabiliza a utilização de recursos que exigem uma preparação antecipada, impossibilitando a adaptaçáo das atividades que dependem destes recursos. Desta forma, o trabalho do professor da SRM, não atinge seu objetivo, pois os recursos e adaptaçóes ficam restritos ao atendimento.

\section{Nos dizeres das professoras da sala comum as considerações sobre o AEE nas SRM}

Verifica-se que as professoras da sala comum sabem que este serviço destina-se aos alunos público-alvo da Educaçáo Especial e tem como um dos objetivos disponibilizar recursos e adaptaçóes, contudo, o que as professoras esperam é que este atendimento possa eliminar as necessidades/dificuldades para desenvolver a aprendizagem dos estudantes. As questóes apontadas mostram-se relevantes, desde que se entenda que o processo de escolarização do estudante que frequenta a SRM é uma responsabilidade que não é limitada à ação do professor especializado, mas de todos os profissionais da escola, assim como da reorganização estrutural deste espaço.

Nos achados da pesquisa, constatou-se que as questôes apontadas evidenciam a necessidade da troca/parceria entre as professoras da SRM e da sala comum, entretanto, esta não aparece como questáo prioritária nos dizeres das professoras. $\mathrm{E}$ quando é destacada como uma das finalidades do AEE nas SRM, as professoras demonstram uma visão equivocada, que não se constitui num trabalho colaborativo no espaço escolar. Estas constataçóes apontam para a necessidade de maiores informaçôes e formaçôes no contexto escolar que tenham como foco o trabalho docente numa perspectiva colaborativa. 


\section{Referências}

ANDRÉ, M. A produção acadêmica sobre formação de professores: um estudo comparativo das dissertaçôes e teses defendidas nos anos 1990 e 2000. Revista Brasileira de Pesquisa sobre Formaçáo Docente. Belo Horizonte, v. 1, n. 1, p. 41-56, ago./dez. 2009.

BAPTISTA, C. R. Ação pedagógica e educação especial: a sala de recursos como prioridade na oferta de serviços especializados. Rev. bras. educ. espec., Marília, v. 17, n. spe1, ago. 2011.

C. R. A ação pedagógica e educação especial: para além do AEE. In: JESUS, D. M. de, BAPTISTA, C. R., CAIADO, K. R. M. (Org.). Prática pedagógica na educaçáo especial: multiplicidade do atendimento Educacional Especializado. Sáo Paulo: Junqueira\&Marin, 2013.

BEYER, H. O. Da Integração escolar a educação inclusiva: implicaçōes pedagógicas. In: BAPTISTA, C. R. (Org.). Inclusão e Escolarizaçáo: múltiplas perspectivas. Porto Alegre: Mediaçấo, 2009.

BRASIL, Ministério da Educação. Secretaria de Educação Especial. Política Nacioanal de Educação Especial na Perspectiva da Educação Inclusiva. Brasília: MEC/SEESP, 2008.

Conselho Nacional de Educaçáo. Câmara de Educação Básica. Resolução CNE/ CEB n.o 4, de 2 de outubro de 2009. Institui Diretrizes Operacionais para o Atendimento Educacional Especializado na Educação Básica, modalidade Educaçáo Especial. Diário Oficial da União, 5 de outubro de 2009.

FREITAS, M. T. A. A abordagem sócio-histórica como orientadora da pesquisa qualitativa. Cad. Pesquisa (online). 2002, n.116, p. 21-39. ISSN 0100-1574. Disponível em: <http://www.scielo.br/pdf/cp/n116/14397>. Acesso em: 15 out. 2014.

FRANCO, M. L. Análise de Conteúdo. 4a ed. Brasília: Liber Livro, 2012.

GARCIA, R. M. C. Deficiência Física e Escolarização: política educacional e implicações para o processo pedagógico. In: MELETTI, S. M. F., KASSAR, M. C. M. (Org.). Escolarizaçáo de alunos com deficiência: desafios e possibilidades. São Paulo: Mercado das letras, 2013.

JESUS, D. M. Formação de Professores para inclusão escolar: instituindo um lugar de conhecimento. In: MENDES, E. G., ALMEIDA, M. A., HAYASHI, M. C. P. I. (Org.). Temas em Educaçáo Especial: conhecimentos para fundamentar a prática. Brasília: CAPES - PROESP, 2008.

MACHADO, R. O Atendimento Educacional Especializado (AEE) e sua repercussáo na mudança das práticas pedagógicas, na perspectiva da educaçáo inclusiva: um estudo sobre as escolas comuns da rede municipal de ensino de Florianópolis/SC. 2013. 185 f. Tese (Doutorado em Educação). Universidade Estadual de Campinas.

MENDES, E. G. Caminhos da pesquisa sobre a Formação de Professores para a inclusão escolar. In: MENDES, E. G., A., Maria A., HAYASHI, M. C. P. I. (Org.). Temas em educaçáa especial: conhecimentos para fundamentar a prática. Brasília: CAPES - PROESP, 2008.

NÓVOA, A. Professores: imagens do futuro presente. Lisboa: Educa, 2011.

SECRETARIA de Educação de Joinville. Dispóe sobre procedimentos em relaçáo às salas de recursos multifuncionais. Instrução Normativa 004/2013.

VYGOTSKY, L. S. Formação social da mente. São Paulo: Martins Fontes. São Paulo, 2007.

\section{Nota}

${ }^{1}$ A maioria dos participantes investigados nesta pesquisa pertence ao gênero feminino, motivo pelo qual se optou em utilizar o feminino genérico.

\section{Correspondência}

Andréia Heiderscheidt Fuck - Escola Municipal João Costa, Prefeitura Municipal de Joinville. Monsenhor Gercino - Jarivatuba, CEP: 89230-290 - Joinville, Santa Catarina - Brasil.

E-mail: 152.andreia@gmail.com - aliciene_machado@hotmail.com

Recebido em 06 de novembro de 2014

Aprovado em 08 de dezembro de 2014

Revista Educação Especial | v. 28 | n. 52 | p. 393-404 | maio/ago. 2015 